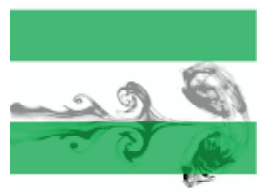

\title{
Experimental Fluid Mechanics 2013
}

TU Liberec, Czech Republic, $19^{\text {th }}-22^{\text {nd }}$ November 2013

\author{
efm.kez.tul.cz
}

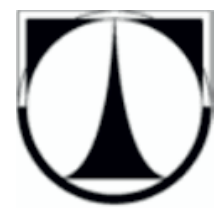

$8^{\text {th }}$ International Conference „Experimental Fluid Mechanics 2013 ” was held at $19^{\text {th }}-22^{\text {nd }}$ November 2013 in Kutná Hora, Czech Republic.

The conference is focused on obtaining overviews of projects under investigation and experimental methods used in the field of fluid mechanic and thermodynamic. Its aim is to organize a network of research workers who are interested in experimental, and also theoretical, work in the field of fluid mechanic and thermodynamic. The conference should contribute the creation of closer contacts and sharing experience in application of various experimental methods, preparation and implementation of experiments, processing of results and numerical simulations of experiments.

The main topics of the conference are:

- Experimental methods used in fluid mechanics and thermodynamics.

- Preparation and implementation of experiments.

- Application of numerical simulation for preparation of experiments, comparison of the results obtained by numerical or analytical methods with experiments.

- Processing the results.

- Experiments in the field of compressible and uncompressible fluid flow, stability of flow, heat and mass transfer, cavitation etc.

- Experiments and measuring carried out on power and regulating equipment.

- Cryogenic fluid dynamics.

Members of Sciences Committee are:

- Assoc. Prof. Tomáš Vít - Head of the committee (TU Liberec, Czech Republic)

- Prof. An-Bang Wang (National Taiwan University, Taiwan)

- Prof. Philippe Fraunie (Université du Sud Toulon-Var, France)

- Prof. Ladislav Skrbek (Charles University, Czech Republic)

- Prof. Václav Kopecký (TU Liberec, Czech Republic)

- Assoc. Prof. Hendric de Lange (Eindhoven Univ. of Technology, The Netherlands)

- Assoc. Prof. Kazimierz Peszynski (Univ. of Technology and Life Sciences in Bydgoszcz, Poland)

- Assoc. Prof. Ludvík Prášil (TU Liberec, Czech Republic)

- Dr. Jan Hrubý (Academy of Science of Czech Republic)

- Dr. Magda Vestfálová (TU Liberec, Czech Republic)

Steering Committee:

- Dr. Petra Dančová (TU Liberec, Czech Republic)

- Eng. Petr Novotný (TU Liberec, Czech Republic)

Keynote lectures for 2013:

- Dr. Tim Persoons (Trinity College, Dublin, Ireland) High Dynamic Range Particle Image Velocimetry Applied to Heat Convection Studies 

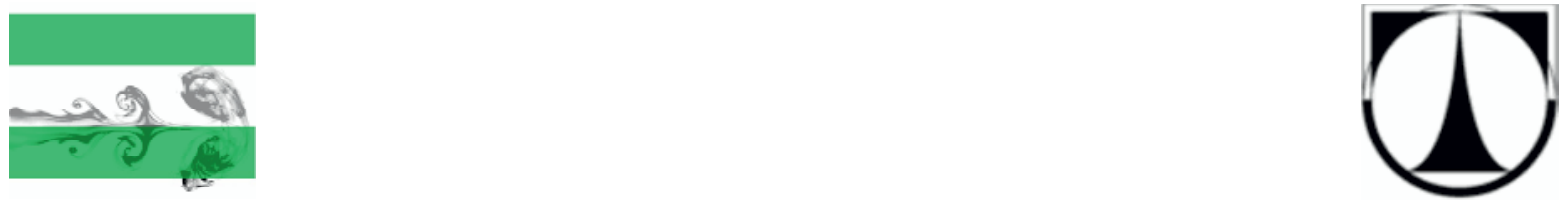

- Dr. H.C. de Lange (Eindhoven University of Technology, Eindhoven, The Netherlands)

Combining the Merits of Experiments and Numerics in Flow Stability Analysis

- Dr. Martin James Jackson (Superfluidity Laboratory, Department of Low Temperature Physics, Charles University Faculty of Mathematics and Physics, Prague, Czech Republic)

Vortex Dynamics and Quantum Turbulence in $3 H e-B$

- Prof Alam Md. Mahbub (Department of Mechanical Engineering and Automation, Harbin Institute of Technology, Shenzhen Graduate School, Shenzhen China)

Wind-Load, Pressure and Velocity Measurements: Post Processing and Discussion

List of Sponsors (in alphabetical order):

- DANTEC DYNAMICS GmbH (www.dantecdynamics.com)

- MECAS ESI s.r.o. (www.esi-group.com)

- MIT s.r.o. (www.mit-laser.cz)

- TSI GmbH (www.tsi.com)

Conference venue:

Every year, the organizers want to prepare the conference at nice and interesting place of the Czech Republic. In 2013, the conference venue was Kutná Hora. The origins of the royal city Kutná Hora are usually linked with the development of a monetary economy in the $13^{\text {th }}$ century, although the dawn of mining came significantly earlier. Surface traces of silver ore were likely to have been discovered in the late $10^{\text {th }}$ century. Shortly after AD 1300 , Kutná Hora became the seat of the central mint of the Czech lands as well as the financial center of the country. Kutná Hora has been included in the UNESCO world heritage list since 1995.

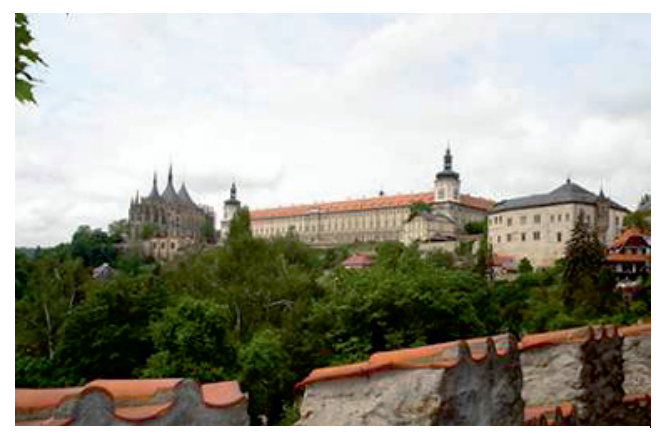

Gallery of the Central Bohemian Region conference venue

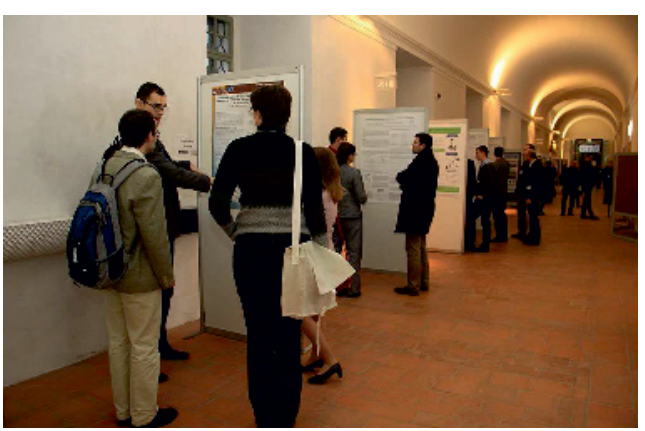

Poster section

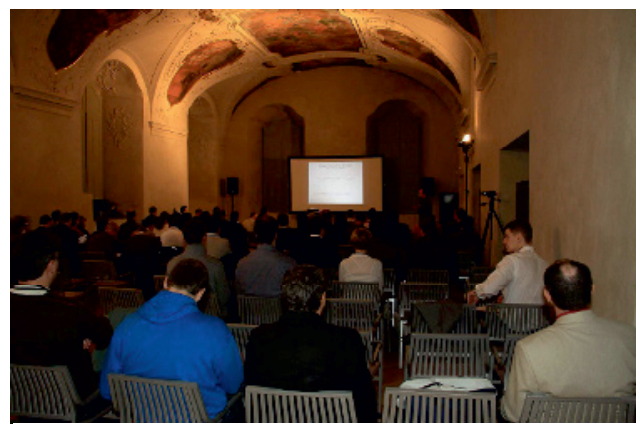

Viev into Lecture room A

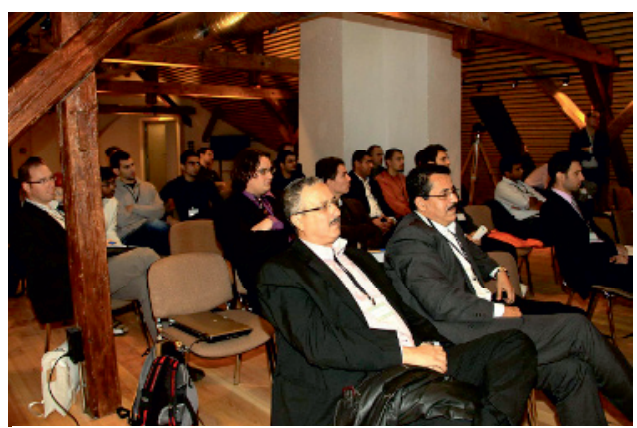

Viev into Lecture room C 